\title{
Platelets in Tissue Regeneration
}

\author{
Ronaldo J. F. C. do Amaral and Alex Balduino \\ Additional information is available at the end of the chapter \\ http://dx.doi.org/10.5772/61184
}

\section{Introduction}

Platelets are especially well known for their thrombotic role. However, besides their role on stopping bleeding, platelets contribute for several mechanisms and steps in wound healing and tissue repair, such as inflammation, angiogenesis, cells proliferation, and differentiation. The potential of platelets to be used therapeutically to assist in wound repair led researchers around the world to look at platelet-based products and their capacity to promote tissue regeneration, in vitro and in vivo. In this chapter, we will discuss the main growth factors present in platelet granules that affect tissue regeneration. In addition, we will consider how platelet-derived products, such as those obtained from platelet-rich plasma (PRP), can be used to enhance tissue regeneration. We will review the applications of this knowledge in clinical trials, and in vivo models, as well as discussing the capacity for platelet products to substitute for classical components of media for in vitro cell culture.

\section{Tissue repair related growth factors in platelets granules}

Approximately, one trillion platelets circulate in the bloodstream of a human adult (4 liters of blood at $3 \times 10^{8}$ platelets $/ \mathrm{ml}$ ). Platelets have a lifespan of approximately 10 days. They are synthesized by megakaryocytic cells in the bone marrow of long bones and approximately $10 \%$ are replenished daily. "Old" and damaged platelets are cleared from the blood by phagocytes in the liver and the spleen [1]. While in the circulation, platelets survey the vasculature for evidence of damage. If damage is perceived, they participate in hemostatic events. When platelets are activated upon vascular injury, they change their discoid form to a more spherical morphology with pseudopods, and they release their granular content [2]. Those are not only related to the coagulation process and hemostasis, but also to tissue repair. The granules are of 3 different types: $\alpha$-granules, dense granules, and lysosymes. $\alpha$-granules 
are the most abundant granule-type in human platelets (50-80 per platelet) and contain a diverse protein repertoire [3] including a variety of molecules with biological activity (Table 1). These molecules are released following platelet activation and play important functional roles at sites of vascular damage.

\begin{tabular}{|c|c|}
\hline CATEGORY & MOLECULE \\
\hline \multirow{5}{*}{ GROWTH FACTORS } & TGF- $\beta$ (transforming growth factor beta) \\
\hline & PDGF (platelet-derived growth factor) \\
\hline & FGF (fibroblast growth factor) \\
\hline & EGF (epidermal growth fator) \\
\hline & VEGF (vascular endothelial growth factor) \\
\hline \multirow{4}{*}{ ADHESION PROTEINS } & Fibrinogen \\
\hline & Fibronectin \\
\hline & Vitronectin \\
\hline & Trombospondin-1 \\
\hline \multirow{4}{*}{ COAGULATION FACTORS } & Factor V \\
\hline & Factor IX \\
\hline & Protein S \\
\hline & Anti-thrombin \\
\hline \multirow{3}{*}{ FIBRINOLYTIC FATORS } & Plasminogen \\
\hline & Plasminogen activatior inhibitor \\
\hline & $\alpha-2$ antiplasmin \\
\hline \multirow{3}{*}{ PROTEASES AND ANTIPROTEASES } & TIMP-4(tissue inhibitor of metalloprotease-4) \\
\hline & Metaloprotease-4 \\
\hline & $\alpha$-1-antitripsin \\
\hline \multirow{2}{*}{ MEMBRANE GLYCOPROTEINS } & CD40-L \\
\hline & P-selectin \\
\hline \multirow{3}{*}{ OTHER PROTEINS } & PF-4 (platelet factor 4 ) \\
\hline & Endostatins \\
\hline & $\beta$-tromboglobulins \\
\hline
\end{tabular}

Table 1. Main bioactive molecules present in platelets alpha granules Adapted from [4].

Many platelet-derived bioactive proteins play critical roles in inflammation, angiogenesis and wound healing. For example, TGF- $\beta 1$, the most abundant isoform of TGF- $\beta$ present in platelets, has an important role in all wound healing phases. It coordinates multiple pathophysiological events including the initial recruitment of inflammatory cells to a site of injury, angiogenesis, re-epitheliazation following damage, and the induction of extracellular matrix production by fibroblasts [5]. PDGF is a chemoattractant molecule for fibroblasts and smooth muscle cells, as well as an inducer of proliferation of mesenchymal cells [6]. FGF-2, the main FGF isoform present in platelets, promotes angiogenesis by supporting 
endothelial cell growth [7]. It is also a potent fibroblast mitogen and induces hyaluronic acid synthesis to facilitate a scarless wound healing [8]. EGF enables mesenchymal cells proliferation, chemotaxis and cytoprotection [9]. VEGF is a pro-angiogenic biomolecule that stimulates blood vessel formation [10], and expression of adhesion proteins that enhance leukocyte adhesion [11]. In fact, a total of more than 300 bioactive agents have been identified that are released from activated platelets [12]. These agents differ in their origin with some components being synthesized in the parent megakaryocyte while others are scavenged from plasma and concentrated in platelet granules [13].

Dense granules contain factors related to platelet activation, such as $\mathrm{Ca}^{2+}$ and $\mathrm{ADP}$, serotonin, histamine, dopamine, and catecolamines. Local release of these components, in response to platelet activation or thrombotic events, results in altered recruitment of inflammatory cell types and altered vascular permeability [14]. Finally, lysosomes contain hydrolytic enzymes and catalases [15]. The nature of the contents of the platelet granules are summarised in MItrugno et al (2015) in this publication.

Platelet activation, with concomitant release of granular contents, happens in parallel with coagulation or thrombosis. The natural participation of platelets and in hemostasis and tissue repair has led to the development of products that could help in those processes.

Due to the variety of possible uses and number of studies, PRP is perhaps the main platelet based product investigated for tissue regeneration purposes. PRP is a platelet concentrate in a small volume of plasma obtained after a centrifugal spin of whole blood to remove red cells and while cells. Regular platelet concentration in peripheral blood is $150-350 \times 10^{6}$ per milliliter. In the context of tissue engineering and wound repair, the term PRP refers to a platelet concentration in plasma above this regular range, that can be injected into a wound site to affect or accelerate repair. The clinical use of PRP, mainly in the cases of bone and soft tissue regeneration, presents a platelet concentration of at least $10^{9}$ per milliliter, which is around 5 times higher than physiological levels [16]. For peri-implant bone regeneration, for example, the recommended platelet concentration is approximately $10^{9}$ per milliliter. In lower concentrations the effect is suboptimal and in higher it is inhibitory [17].

The therapeutic action of platelet concentrates derives from the release of factors involved in tissue repair upon platelet activation. The clot that is formed during that activation may also play a role of a temporary extracellular matrix which will allow cells proliferation and differentiation [16]. In that case, an elevated platelet concentration would be expected to generate an elevated local concentration of released bioactive factors. However the correlation between the platelet concentration and the concentration of released bioactive agents may not be exact, due to variations between blood donors [18], or between platelet preparation methods [19]. Moreover, some growth factors that act in tissue repair are also present in plasma. Such growth factors include HGF and IGF-1. Consequently, the concentrations of these factors at sites of wounds may only be slightly altered according to the platelet concentration [20]. Generally, it is considered that a platelet concentration 5 times higher than in peripheral blood can lead to an enhanced local concentration of growth factors that varies from 3 to 5 times in excess of normal pathophysiological levels [4]. Thus, by serving as a reservoir of concentrated growth factors involved in cell proliferation and differentiation, platelet concentrates can 
contribute to tissue growth and repair. In a similar manner, platelet-derived bioactive products may find use in cell culture protocols.

\section{How platelet products can improve cell culture}

Since the beginning of cell culture techniques, many innovations were designed to optimize the process of cell expansion in vitro, analyzing their differentiation capacity, as well as their response to chemicals and promising pharmaceutical molecules. With time, the field improved. Plastics, glasses, bioreactors and engineering technology evolved a lot, at the same time that the biological field also evolved.

Methods to grow cells in vitro try to reproduce appropriately all physiological conditions that are observed in vivo, and try to mimic it in vitro. The culture medium is the source of soluble factors that will enable cell growth and survival. Classical cell culture media are comprised of a basal balanced salt solution such as MEM (Eagle's minimal essential medium), DMEM (Dulbecco's modified Eagle's medium), IMDM (Iscove's modified DMEM), RPMI (Roswell Park Memorial Institute medium), Medium-199, HamF12 and McCoy's medium. Although they provide inorganic salts, amino acids, vitamins and glucose, a protein-rich supplement is required to provide growth factors. Traditionally, Fetal Bovine Serum (FBS) is added to the basal medium [21] as the main source of growth factors to stimulate cell proliferation; FBS contains transport proteins carrying hormones (e.g. transcortin), minerals, trace elements (e.g. transferrin), and lipids (e.g. lipoproteins). In addition, FBS contain attachment and spreading factors, acting as germination points for cell attachment; and stabilizing and detoxifying factors needed to maintain $\mathrm{pH}$ or to inhibit proteases either directly, such as $\alpha$-antitrypsin or $\alpha 2$ macroglobulin, or indirectly, by acting as an unspecific sink for proteases and other (toxic) molecules [22]. FBS is obtained by cardiac puncture of bovine fetuses without anaesthesia. Jochems strongly discussed the ethical issues on the use of FBS. The use of cell culture is strongly recommended as an alternative to animal experimentation. However, the requirement for FBS, obtained from animal sources, end up making the concept of cell culture as an alternative to animal experimentation somewhat unethical [23].

Besides the ethical issues, scientific issues are also pointed on the use of FBS. Firstly, lot-to-lot variations make it necessary to test samples before purchase, as its molecular composition of FBS may vary [24]. FBS might interfere with cells genotype and phenotype, influencing experimental outcome. For example, it can promote cell proliferation in fibroblasts, whilst inhibiting it in epithelial cells [25]. It can be contaminated with viruses, bacteria, mycoplasmas, yeast, fungi, immunoglobulins, endotoxins, and possibly prions [26], contraindicating it for use for cells that would be further transplanted into humans. FBS is not totally chemically defined, as many substances present in it have not yet been characterized [27], some don't have their function fully elucidated, and others may even be toxic [28].

Serum, obtained from clotted whole blood, is known to be more suitable to cell culture than plasma from the same organism; despite the difficulty in obtaining it in large quantities. This is likely to be due to the release of proteins and growth factors from activated platelets during 
the clotting process [29], [30].Therefore, PRP, platelet lysates and other platelet-derived products can substitute FBS in cell culture. As the platelets are present in an elevated concentration, the growth factors important for cell culture are also more concentrated, as already discussed in this chapter. Finally, platelets can be easily obtained from human sources and therefore better mimic the effects of serum in human cells. Thinking of cell therapy, it can be used for growing cells that would be later transplanted into humans, especially when in an autologous approach.

\section{How platelets can be used to improve tissue repair}

Platelet concentrates, with the concentration of $5 \times 10^{10}$ platelets / unit are usually used for the treatment and prevention of severe hemorrhage [31]. The use of blood products for wound closure and stimulation of repair, such as fibrin glues, was first described in the 1970s [32]. The platelet gel emerged in the 1990s as a cheaper and autologous alternative compared to fibrin glues [33]. In 1987, PRP emerged as a product of autologous transfusion after open heart surgery, to prevent the need for a homologous product [34]. In 1998, Marx et al. described the use of platelets as an accelerator of tissue repair/regeneration, in that case bone formation in bone grafts for maxillofacial surgery [35].

Since then, most of the studies have shown an increase in bone repair, musculoskeletal tissues (muscles, tendons, and cartilage) and other "soft" tissues when platelet concentrates are used [36]. In the case of bone repair in maxillofacial surgery, the use of a platelet product efficacy and safety have been proven. In that case, only 9 out of 1,287 maxillae and mandible short implants $(<8,5 \mathrm{~mm})$ from 661 patients between 2001 and 2008 had been lost. All implants had been embedded in liquid PRGF (plasma-rich in growth fators). Briefly, PRGF is obtained by centrifugation of whole blood collected in $9 \mathrm{ml}$ tubes containing sodium citrate at $580 \mathrm{xg}$ for 8 minutes. Next, the $1 \mathrm{ml}$ fraction above red cell fraction is collected and activated with calcium chloride [37]. Although platelet products lack osteoinductive factors as BMPs, they can enhance bone formation. When PRP is added to human autogenous bone grafts, the bone density is higher, higher the proportion of mature bone and lesser osteoclast resorption, compared to size and age-matched grafts without PRP after 4 months of surgery [36]. Human PRP with the presence of peripheral blood mononucleated cells had its angiogenic properties proven in a nude animal model of critical size calvarial defect. Moreover, when it has been used synergistically with BMP-2, the effect on bone healing was augmented, as observed by histology, bone mineral density and bone mineral content after 8 weeks of implantation [38]. As said before, the induction of bone regeneration is more effective when PRP is used with approximately 1 million platelets per microliter. This was shown in a study where femurs of New Zealand white rabbits receiving an titanium implant where treated or not with autologous PRP. Lower concentrations than 1 million platelets per microliter resulted in suboptimal peri-implant bone formation, whereas higher concentrations caused an inhibitory effect [17]. In addition, mesenchymal cells treated with PRP are also able to promote better repair and bone maturation in mandibular bone defects models, being pointed as an alternative to autogenous grafts. This has been shown when bone defects of canine mandible were filled 
with autologous PRP gel, autologous PRP gel with bone-marrow MSCs or autogenous particulate cancellous bone and marrow (PCBM). Briefly, PRP was obtained by 50mL blood collection in heparin, followed by two centrifugation steps which resulted in platelet concentration $438 \%$ above baseline. PRP activation was performed by adding thrombin/calcium solution. Increased bone formation and neovascularization was observed in the PRP plus MSC group. [39].

In muscle injuries, some factors present in PRP such as IGF-1 and bFGF can accelerate tissue repair. In contrast, TGF- $\beta$ may lead to a fibrotic repair, increasing the possibility of the recurrence of new lesions [40]. Although mice with muscular injuries have demonstrated functional improvement when treated with high-frequency ultrasound-treated PRP, in order to lyse platelets and release of growth factor [41]. A preliminary study on muscle strain injuries in professional sportsman showed significant increase in the recovery time from injury when treated with autologous conditioned serum (ACS). ACS was obtained by blood collection without anti-coagulants followed by incubation and centrifugation for the retrieving of the serum [42]. Nonetheless, the action of PRP in muscle injuries still requires further investigation [43]. The first double-blinded, randomized, placebo controlled PRP clinical study on acute muscle injury, did not confirm the benefits for the use of PRP to enable the return to sports activities by athletes. In this case, PRP was prepared using a commercially available system (Arthrex double syringe ACP system) according to the manufacturer's instructions, and apparently was not activated prior to injection [44]. However, the methodology used in this work has been questioned, due to delayed administration and low dosage of PRP injections. The authors replied that there is no consensus on time of PRP injections, as well as that their PRP preparation method was in accordance with the literature [45].

Animal studies [46], [47] and human trials in tendon injuries show positive results through the use of PRP [48]-[50]. Although clinical trials with appropriate methodologies have not yet proven the effectiveness of PRP in this type of injury [51], localized platelet delivery can induce mobilization of circulating cells to sites of rat tendon injuries with concomitant increase in collagen synthesis [52]. In vitro, platelets can induce proliferation, collagen synthesis [53] and release of angiogenic factors in human tenocytes [54].A systematic review stated there were strong evidence against PRP injection for chronic lateral epicondylar tendinopathy. In a total of 6 studies, 5 showed no significant benefit at the final follow-up, while 1 presented benefits for PRP injections compared to corticosteroid injection [55]. However, the results presented in that review have been questioned [56]. Surprisingly, another systematic review, selecting 9 studies, concluded there was limited but evolving evidence to support PRP injections in lateral epicondylitis, suggesting that further studies regarding the preparation of PRP as well as the timing of the interventions are needed [57].

Cartilage, as an avascular tissue, and so injuries are usually critical and difficult to repair. Consequently, there is a need for new regenerative methods to address the specific demands imposed by cartilaginous injuries [58]. In 2003, PRGF was first used in a case of cartilaginous avulsion in a football player, causing an accelerated and rapid repair, which enabled the athlete's earlier return to sport activities [59]. Intra-articular PRP injections in patients with chronic cartilage degeneration also demonstrated positive results evaluated by clinical score 
methods as IKDC and EQ-VAS. In those studies, PRP was prepared by two-centrifugation steps which increased platelet concentration of $600 \%$ comparing to whole blood counting, and was activated by calcium solution prior to injection [60], [61]. On the other hand, in vitro analyses on chondrocytes proliferation and chondrogenic induction generated controversial results in the literature: In general, PRP induced chondrocyte proliferation [62]. Regarding chondrogenic induction, PRP appeared as an inducer [63], [64], while contradictory results showing the promotion of fibrogenic phenotype have also been observed [65], [66]. These antitheses may be related to different methodologies for PRP production, and therefore requires a better assessment of the PRP effect on chondrogenic cells.

PRP has also shown to induce mesenchymal stem cells (MSCs) proliferation. Regarding induction of osteogenesis on MSCs, mouse MSCs were treated with activated by thrombin/ calcium solution human PRP or washed platelets (WPLT), where the platelets had been suspended in phosphate saline rather than plasma, with equal platelets concentration, 4 times above the baseline. Interestingly, both stimulated cells proliferation in earlier time points, while WPLT induced higher proliferation than PRP in later time points. Alternatively, ALP activity and collagen type I expression, those indicatives of osteogenic differentiation, were increased in PRP rather than WPLT [67]. In others studies, PRP gel could induce osteocalcin and collagen type 1 expression in rat MSC [68], as well as activated PRP, with platelet concentration 4 times higher the baseline, induced greater human MSC mineralization [69]. Interestingly, when the growth factors present in PRP are released in a controlled manner, through the association of PRP with alginate hydrogel, human MSCs alkaline phosphatase activity is induced [70]. As for chondrogenic induction in vitro, mRNA levels for aggrecan, Sox-9, and Runx2 were increased in buffered, i.e. inactivated, PRP treated human MSCs [71]. Subchondral bone MSCs cultured in a 3D model also showed chondrogenic potential induced by PRP (activated by freezing and thawing process), but not osteogenic or adipogenic [72]. Moreover, PRP associated with MSCs was able to induce chondrogenesis in vitro and in vivo in full-thickness rabbit articular cartilage injury model [73]. Recently, a systematic review selected 27 articles analyzing the role of PRP on MSCs in vitro proliferation and differentiation, in comparison to FBS. It has been seen that PRP stimulates cells proliferation, preserves their immunomodulatory capacity and may delay the acquirement of a senescent phenotype. The majority of the studies also showed that PRP maintains cells adipogenic, osteogenic and chondrogenic differentiation capacity, in fewer cases enhanced it, while in rare cases diminished the adipogenic differentiation capacity [74].

Platelets have been shown to play an important role in the repair of many different tissues such as skin [75], nervous tissue [76], corneal [77], myocardial [78], and vascular [79]. In addition, platelet-derived products demonstrate distinct antimicrobial effects [80], and contribute to orthopedic repair [81] and plastic surgery applications [82]. It is worth noting the potential for therapeutic effects in sports medicine, as the need for elite athletes to recover quickly from injuries and achieve their regular level of efficiency is huge. PRP use is currently allowed by the global anti-doping agency [83].

There have been no reports of serious health problems arising after the therapeutic use of PRP so far, but despite evidence demonstrating its positive effects, especially in repair of muscu- 
loskeletal injuries, there are few published clinical studies, and even smaller the number of works with sufficient methodological quality to ensure evidence-based decision-making use of PRP [43]. Likewise, there is still a need for basic studies to better understand some still open issues, such as the optimal concentration of platelets, the harm or the benefits of the presence of leukocytes, a possible combination of recombinant proteins with PRP [15] and analysis of its action at the cellular level.

\section{The need of standardization}

Due to the variety of protocols, many classifications are used to characterize platelet preparations for tissue engineering purposes. Many groups refer generically to platelets used in tissue engineering applications as Platelet-Rich Plasma (PRP). However, this can cause confusion, since many biomedical researchers use the PRP abbreviation to refer to a simple enrichment by centrifugation of whole blood to remove red blood cells and leukocytes. Nonetheless, tissue engineers have adopted the term PRP to refer to platelet concentrates that can be re-injected to a site of tissue injury with or without modification or activation. Moreover, additional acronyms are used to sub classify the platelet preparations used in tissue injury-studies. Among these classifications, we can find: PDWHF (platelet derived wound healing factors) [84], L- PRP (leukocyte and platelet - rich plasma) [85], PRFM (plasma rich fibrin matrix) [86], PRGF (plasma rich in growth factors) [87], among others.

Likewise, the PRP gel preparation used in tissue engineering applications cannot be referred to as a " fibrin glue", as the clot formed in the PRP activation contain the same components and at similar concentrations to that found in a native blood clot and consists primarily of fibrin, fibronectin and vitronectin, besides the bioactive molecules. The fibrin glue is only considered a concentrate of fibrinogen, which is polymerized by thrombin and calcium [16]. This platelet gel was originally used as a substitute to fibrin glue in oral and maxillofacial surgery [33]. It was also used in cutaneous chronic wounds [88], including diabetic ulcers [89], degenerative disorders of the knee [90], gynecologic, cardiac, and general surgical procedures [91].

Various commercial systems for the preparation of autologous platelet products for local injection into wound sites have been developed. Among the main ones are: SmartPrep ${ }^{\circledR} 2$ APC +TM (Harvest Technologies), Biomet GPS III @ (Biomet Manufacturing Corp.), Arthrex ACP ${ }^{\circledR}$ (Arthrex Inc), Cascade ${ }^{\circledR}$ platelet - rich fibrin matrix (Musculoskeletal Trasnplant Foundation), Cascade ${ }^{\circledR}$ platelet - rich plasma therapy (Musculoskeletal Trasnplant Foundation), BTI plasma rich in growth factors (PRGF) (Biotechnology Institute) and Magellan ${ }^{\circledR}$ Autologous Platelet Separator System (Arteriocyte) [92]. Despite such variety, the basic formulation of PRP consists of primarily autologous blood collection in the presence of anticoagulants. After collection, the blood is centrifuged once or twice in order to separate the plasma with platelets from erythrocytes and leukocytes and concentrate them. After the second centrifugation, part of the plasma is used to resuspend the platelet concentrate, formulating the final PRP. The portion of the plasma that is not used in this ressupension is commonly described as platelet- 
poor plasma (PPP). The release of growth factors contained in platelets granules occurs following activation of the PRP with exogenous thrombin, collagen, or calcium chloride, forming a clot. Some methodologies also may use freeze-thawing cycles or sonication by ultrasound treatment in order to disrupt platelets membrane and release of the growth factors. In other cases, platelets may not be activated at all. Calcium chloride is important to enable fibrin polymerization and thrombin generation by the endogenous coagulation cascade. The final product, i.e. the supernatant liquid without the clot, is actually a serum derived from PRP [4]. Both commercial and non-commercial forms may vary on the speed and number of centrifugation steps to concentrate the platelets, the usage or not of anticoagulant, the type of anticoagulant, the presence of leukocytes, which may release matrix metalloproteinase and reactive oxygen species that can increase tissue damage, and the substance that will induce platelet activation. In the end, these variations generate diversity in types, concentration and speed of the release of growth factors, which may explain different results among papers [93]. In order to normalize and standardize platelets products for tissue engineering purposes, mainly by the platelet concentration, activation (whether it occurs or not an how), and presence of white blood cells, some classification systems have been proposed [83], [94].In summary, platelets act as reservoirs of growth factors and bioactive agents. The localized application of concentrated preparations of these reagents from autologous platelet donations appears to facilitate and accelerate wound healing and tissue repair. Some controversy exists as to the effectiveness of this treatment. However, significant variations in the platelet preparations, mainly platelet concentration and activation, may explain some or all of the variations.

\section{Author details}

Ronaldo J. F. C. do Amaral ${ }^{1,2}$ and Alex Balduino ${ }^{2,3^{*}}$

*Address all correspondence to: alex.balduino@excellion.com.br

1 Universidade Federal do Rio de Janeiro, RJ, Brazil

2 Excellion Labs AMIL/UnitedHealth Group, RJ, Brazil

3 Laboratório de Biologia e Tecnologia Celular, Universidade Veiga de Almeida, RJ, Brazil

\section{References}

[1] J. E. Kaplan and T. M. Saba, "Platelet removal from the circulation by the liver and spleen.," Am. J. Physiol., vol. 235, no. 3, pp. H314-20, Sep. 1978.

[2] J. W. M. Heemskerk, E. M. Bevers, and T. Lindhout, "Platelet activation and blood coagulation.," Thromb. Haemost., vol. 88, no. 2, pp. 186-93, Aug. 2002. 
[3] A. Zufferey, D. Schvartz, S. Nolli, J.-L. Reny, J.-C. Sanchez, and P. Fontana, "Characterization of the platelet granule proteome: evidence of the presence of $\mathrm{MHC1}$ in alpha-granules.," J. Proteomics, vol. 101, pp. 130-40, Apr. 2014.

[4] T. E. Foster, B. L. Puskas, B. R. Mandelbaum, M. B. Gerhardt, and S. a Rodeo, "Platelet-rich plasma: from basic science to clinical applications.," Am. J. Sports Med., vol. 37, no. 11, pp. 2259-72, Nov. 2009.

[5] M. Pakyari, A. Farrokhi, M. K. Maharlooei, and A. Ghahary, "Critical Role of Transforming Growth Factor Beta in Different Phases of Wound Healing.," Adv. wound care, vol. 2, no. 5, pp. 215-224, Jul. 2013.

[6] J. Donovan, D. Abraham, and J. Norman, "Platelet-derived growth factor signaling in mesenchymal cells.," Front. Biosci. (Landmark Ed., vol. 18, pp. 106-19, Jan. 2013.

[7] A. Sahni, O. D. Altland, and C. W. Francis, "FGF-2 but not FGF-1 binds fibrin and supports prolonged endothelial cell growth.," J. Thromb. Haemost., vol. 1, no. 6, pp. 1304-10, Jun. 2003.

[8] S. Akita, K. Akino, and A. Hirano, "Basic Fibroblast Growth Factor in Scarless Wound Healing.," Adv. wound care, vol. 2, no. 2, pp. 44-49, Mar. 2013.

[9] J. Berlanga-Acosta, J. Gavilondo-Cowley, P. López-Saura, T. González-López, M. D. Castro-Santana, E. López-Mola, G. Guillén-Nieto, and L. Herrera-Martinez, “Epidermal growth factor in clinical practice - a review of its biological actions, clinical indications and safety implications.," Int. Wound J., vol. 6, no. 5, pp. 331-46, Oct. 2009.

[10] D. I. R. Holmes and I. Zachary, "The vascular endothelial growth factor (VEGF) family: angiogenic factors in health and disease.," Genome Biol., vol. 6, no. 2, p. 209, Jan. 2005.

[11] J.-K. Min, Y.-M. Lee, J. H. Kim, Y.-M. Kim, S. W. Kim, S.-Y. Lee, Y. S. Gho, G. T. Oh, and Y.-G. Kwon, "Hepatocyte growth factor suppresses vascular endothelial growth factor-induced expression of endothelial ICAM-1 and VCAM-1 by inhibiting the nuclear factor-kappaB pathway.," Circ. Res., vol. 96, no. 3, pp. 300-7, Feb. 2005.

[12] J. A. Coppinger, G. Cagney, S. Toomey, T. Kislinger, O. Belton, J. P. McRedmond, D. J. Cahill, A. Emili, D. J. Fitzgerald, and P. B. Maguire, "Characterization of the proteins released from activated platelets leads to localization of novel platelet proteins in human atherosclerotic lesions.," Blood, vol. 103, no. 6, pp. 2096-104, Mar. 2004.

[13] S. W. Whiteheart, "Platelet granules: surprise packages.," Blood, vol. 118, no. 5, pp. 1190-1, Aug. 2011.

[14] D. Schumacher, B. Strilic, K. K. Sivaraj, N. Wettschureck, and S. Offermanns, "Platelet-derived nucleotides promote tumor-cell transendothelial migration and metastasis via P2Y2 receptor.," Cancer Cell, vol. 24, no. 1, pp. 130-7, Jul. 2013. 
[15] A. T. Nurden, P. Nurden, M. Sanchez, I. Andia, and E. Anitua, "Platelets and wound healing.," Front. Biosci., vol. 13, pp. 3532-48, Jan. 2008.

[16] R. E. Marx, "Platelet-rich plasma (PRP): what is PRP and what is not PRP?," Implant Dent., vol. 10, no. 4, pp. 225-8, Jan. 2001.

[17] G. Weibrich, T. Hansen, W. Kleis, R. Buch, and W. E. Hitzler, "Effect of platelet concentration in platelet-rich plasma on peri-implant bone regeneration.," Bone, vol. 34, no. 4, pp. 665-71, Apr. 2004.

[18] B. L. Eppley, J. E. Woodell, and J. Higgins, "Platelet Quantification and Growth Factor Analysis from Platelet-Rich Plasma: Implications for Wound Healing," Plast. Reconstr. Surg., pp. 1502-1508, Nov. 2004.

[19] R. Zimmermann, R. Jakubietz, M. Jakubietz, E. Strasser, A. Schlegel, J. Wiltfang, and R. Eckstein, "Different preparation methods to obtain platelet components as a source of growth factors for local application.," Transfusion, vol. 41, no. 10, pp. 121724, Oct. 2001.

[20] E. Anitua, M. Sánchez, M. M. Zalduendo, M. de la Fuente, R. Prado, G. Orive, and I. Andía, "Fibroblastic response to treatment with different preparations rich in growth factors.," Cell Prolif., vol. 42, no. 2, pp. 162-70, Apr. 2009.

[21] Z. Yang and H. Xiong, "Culture Conditions and Types of Growth Media for Mammalian Cells," Biomed. Tissue Cult., pp. 3-18, 2012.

[22] D. Brunner, J. Frank, H. Appl, H. Schöffl, W. Pfaller, and G. Gstraunthaler, "Serumfree cell culture: the serum-free media interactive online database.," ALTEX, vol. 27, no. 1, pp. 53-62, Jan. 2010.

[23] C. E. a Jochems, J. B. F. van der Valk, F. R. Stafleu, and V. Baumans, "The use of fetal bovine serum: ethical or scientific problem?," Altern. Lab. Anim., vol. 30, no. 2, pp. 219-27, 2002.

[24] K. V. Honn, J. A. Singley, and W. Chavin, "Fetal Bovine Serum: A Multivariate Standard," Exp. Biol. Med., vol. 149, no. 2, pp. 344-347, Jun. 1975.

[25] P. A. Knepper, C. S. Mayanil, W. Goossens, D. C. McLone, and E. Hayes, "The presence of transcription factors in fetal bovine sera.," In Vitro Cell. Dev. Biol. Anim., vol. 34, no. 2, pp. 170-3, Feb. 1998.

[26] J. Hodgson, "Fetal Bovine Serum Revisited," Bio/Technology, vol. 11, no. 1, pp. 49-53, Jan. 1993.

[27] Y. Pan, P. K. Bender, R. M. Akers, and K. E. Webb, “One or more serum factors promote peptide utilization in cultured animal cells.," J. Nutr., vol. 128, no. 4, pp. 744-50, Apr. 1998.

[28] D. Barnes and G. Sato, "Serum-free cell culture: a unifying approach," Cell, vol. 22, no. 3, pp. 649-655, Dec. 1980. 
[29] S. D. Balk, S. P. Levine, L. L. Young, M. M. LaFleur, and N. M. Raymond, "Mitogenic factors present in serum but not in plasma.," Proc. Natl. Acad. Sci. U. S. A., vol. 78, no. 9, pp. 5656-60, Sep. 1981.

[30] D. Gospodarowicz and C. R. Ill, “Do plasma and serum have different abilities to promote cell growth?," Proc. Natl. Acad. Sci. U. S. A., vol. 77, no. 5, pp. 2726-30, May 1980.

[31] D. M. Dohan Ehrenfest, L. Rasmusson, and T. Albrektsson, "Classification of platelet concentrates: from pure platelet-rich plasma (P-PRP) to leucocyte- and platelet-rich fibrin (L-PRF).," Trends Biotechnol., vol. 27, no. 3, pp. 158-67, Mar. 2009.

[32] H. Matras, "Fibrin seal: the state of the art.," J. Oral Maxillofac. Surg., vol. 43, no. 8, pp. 605-11, Aug. 1985.

[33] D. H. Whitman, R. L. Berry, and D. M. Green, "Platelet gel: an autologous alternative to fibrin glue with applications in oral and maxillofacial surgery.," J. Oral Maxillofac. Surg., vol. 55, no. 11, pp. 1294-9, Nov. 1997.

[34] M. Ferrari, S. Zia, M. Valbonesi, F. Henriquet, G. Venere, S. Spagnolo, M. A. Grasso, and I. Panzani, "A new technique for hemodilution, preparation of autologous platelet-rich plasma and intraoperative blood salvage in cardiac surgery.," Int. J. Artif. Organs, vol. 10, no. 1, pp. 47-50, Jan. 1987.

[35] R. E. Marx, E. R. Carlson, R. M. Eichstaedt, S. R. Schimmele, J. E. Strauss, and K. R. Georgeff, "Platelet-rich plasma: Growth factor enhancement for bone grafts.," Oral Surg. Oral Med. Oral Pathol. Oral Radiol. Endod., vol. 85, no. 6, pp. 638-46, Jun. 1998.

[36] R. E. Marx, "Platelet-rich plasma: evidence to support its use," J. Oral Maxillofac. Surg., vol. 62, no. 4, pp. 489-496, Apr. 2004.

[37] E. Anitua and G. Orive, "Short Implants in Maxillae and Mandibles: A Retrospective Study With 1 to 8 Years of Follow-Up," J. Periodontol., vol. 81, no. 6, pp. 819-826, Jun. 2010.

[38] E.-J. Park, E.-S. Kim, H.-P. Weber, R. F. Wright, and D. J. Mooney, “Improved bone healing by angiogenic factor-enriched platelet-rich plasma and its synergistic enhancement by bone morphogenetic protein-2.," Int. J. Oral Maxillofac. Implants, vol. 23, no. 5, pp. 818-26, Jan. 2008.

[39] Y. Yamada, M. Ueda, T. Naiki, M. Takahashi, K.-I. Hata, and T. Nagasaka, “Autogenous injectable bone for regeneration with mesenchymal stem cells and platelet-rich plasma: tissue-engineered bone regeneration.," Tissue Eng., vol. 10, no. 5-6, pp. 955964, 2004.

[40] J. Menetrey, C. Kasemkijwattana, C. S. Day, P. Bosch, M. Vogt, F. H. Fu, M. S. Moreland, and J. Huard, "Growth factors improve muscle healing in vivo.," J. Bone Joint Surg. Br., vol. 82, no. 1, pp. 131-7, Jan. 2000. 
[41] J. W. Hammond, R. Y. Hinton, L. A. Curl, J. M. Muriel, and R. M. Lovering, "Use of autologous platelet-rich plasma to treat muscle strain injuries.," Am. J. Sports Med., vol. 37, no. 6, pp. 1135-42, Jun. 2009.

[42] T. Wright-Carpenter, P. Klein, P. Schäferhoff, H. J. Appell, L. M. Mir, and P. Wehling, "Treatment of muscle injuries by local administration of autologous conditioned serum: a pilot study on sportsmen with muscle strains.," Int. J. Sports Med., vol. 25, no. 8, pp. 588-93, Nov. 2004.

[43] L. Engebretsen, K. Steffen, J. Alsousou, E. Anitua, N. Bachl, R. Devilee, P. Everts, B. Hamilton, J. Huard, P. Jenoure, F. Kelberine, E. Kon, N. Maffulli, G. Matheson, O. Mei-Dan, J. Menetrey, M. Philippon, P. Randelli, P. Schamasch, M. Schwellnus, A. Vernec, and G. Verrall, "IOC consensus paper on the use of platelet-rich plasma in sports medicine.," Br. J. Sports Med., vol. 44, no. 15, pp. 1072-81, Dec. 2010.

[44] G. Reurink, G. J. Goudswaard, M. H. Moen, A. Weir, J. A. N. Verhaar, S. M. A. Bierma-Zeinstra, M. Maas, and J. L. Tol, "Platelet-rich plasma injections in acute muscle injury.," N. Engl. J. Med., vol. 370, no. 26, pp. 2546-7, Jun. 2014.

[45] E. Anitua, M. Sánchez, and S. Padilla, "More on platelet-rich plasma injections in acute muscle injury.," N. Engl. J. Med., vol. 371, no. 13, p. 1264, Sep. 2014.

[46] P. Aspenberg and O. Virchenko, "Platelet concentrate injection improves Achilles tendon repair in rats.," Acta Orthop. Scand., vol. 75, no. 1, pp. 93-9, Feb. 2004.

[47] L. V Schnabel, H. O. Mohammed, B. J. Miller, W. G. McDermott, M. S. Jacobson, K. S. Santangelo, and L. A. Fortier, "Platelet rich plasma (PRP) enhances anabolic gene expression patterns in flexor digitorum superficialis tendons.," J. Orthop. Res., vol. 25, no. 2, pp. 230-40, Feb. 2007.

[48] K. Gaweda, M. Tarczynska, and W. Krzyzanowski, "Treatment of Achilles tendinopathy with platelet-rich plasma.," Int. J. Sports Med., vol. 31, no. 8, pp. 577-83, Aug. 2010 .

[49] A. Mishra and T. Pavelko, "Treatment of chronic elbow tendinosis with buffered platelet-rich plasma.," Am. J. Sports Med., vol. 34, no. 11, pp. 1774-8, Nov. 2006.

[50] P. S. Randelli, P. Arrigoni, P. Cabitza, P. Volpi, and N. Maffulli, "Autologous platelet rich plasma for arthroscopic rotator cuff repair. A pilot study.," Disabil. Rehabil., vol. 30, no. 20-22, pp. 1584-9, Jan. 2008.

[51] R. J. de Vos, P. L. J. van Veldhoven, M. H. Moen, A. Weir, J. L. Tol, and N. Maffulli, "Autologous growth factor injections in chronic tendinopathy: a systematic review.," Br. Med. Bull., vol. 95, pp. 63-77, Jan. 2010.

[52] Y. Kajikawa, T. Morihara, H. Sakamoto, K. Matsuda, Y. Oshima, A. Yoshida, M. Nagae, Y. Arai, M. Kawata, and T. Kubo, "Platelet-rich plasma enhances the initial mobilization of circulation-derived cells for tendon healing.," J. Cell. Physiol., vol. 215, no. 3, pp. 837-45, Jun. 2008. 
[53] M. de Mos, A. E. van der Windt, H. Jahr, H. T. M. van Schie, H. Weinans, J. a N. Verhaar, and G. J. V. M. van Osch, "Can platelet-rich plasma enhance tendon repair? A cell culture study.," Am. J. Sports Med., vol. 36, no. 6, pp. 1171-8, Jun. 2008.

[54] E. Anitua, I. Andía, M. Sanchez, J. Azofra, M. del Mar Zalduendo, M. de la Fuente, P. Nurden, and A. T. Nurden, "Autologous preparations rich in growth factors promote proliferation and induce VEGF and HGF production by human tendon cells in culture.," J. Orthop. Res., vol. 23, no. 2, pp. 281-6, Mar. 2005.

[55] R.-J. de Vos, J. Windt, and A. Weir, "Strong evidence against platelet-rich plasma injections for chronic lateral epicondylar tendinopathy: a systematic review.," $\mathrm{Br}$. J. Sports Med., pp. 952-956, 2014.

[56] T. Gosens and A. K. Mishra, "Editorial in response to the systematic review by de Vos et al: 'Strong evidence against platelet-rich plasma injections for chronic lateral epicondylar tendinopathy: a systematic review,'” Br J Sport. Med, vol. 48, no. 12, pp. 945-946, 2014.

[57] Z. Ahmad, R. Brooks, S.-N. Kang, H. Weaver, I. Nunney, G. Tytherleigh-Strong, and N. Rushton, "The effect of platelet-rich plasma on clinical outcomes in lateral epicondylitis.," Arthroscopy, vol. 29, no. 11, pp. 1851-62, Nov. 2013.

[58] L. Nelson, J. Fairclough, and C. W. Archer, "Use of stem cells in the biological repair of articular cartilage.," Expert Opin. Biol. Ther., vol. 10, no. 1, pp. 43-55, Jan. 2010.

[59] M. Sánchez, J. Azofra, E. Anitua, I. Andía, S. Padilla, J. Santisteban, and I. Mujika, "Plasma rich in growth factors to treat an articular cartilage avulsion: a case report.," Med. Sci. Sports Exerc., vol. 35, no. 10, pp. 1648-52, Oct. 2003.

[60] E. Kon, R. Buda, G. Filardo, A. Di Martino, A. Timoncini, A. Cenacchi, P. M. Fornasari, S. Giannini, and M. Marcacci, "Platelet-rich plasma: intra-articular knee injections produced favorable results on degenerative cartilage lesions.," Knee Surg. Sports Traumatol. Arthrosc., vol. 18, no. 4, pp. 472-9, Apr. 2010.

[61] G. Filardo, E. Kon, R. Buda, A. Timoncini, A. Di Martino, A. Cenacchi, P. M. Fornasari, S. Giannini, and M. Marcacci, "Platelet-rich plasma intra-articular knee injections for the treatment of degenerative cartilage lesions and osteoarthritis.," Knee Surg. Sports Traumatol. Arthrosc., vol. 19, no. 4, pp. 528-35, Apr. 2011.

[62] A. Drengk, A. Zapf, E. K. Stürmer, K. M. Stürmer, and K.-H. Frosch, “Influence of platelet-rich plasma on chondrogenic differentiation and proliferation of chondrocytes and mesenchymal stem cells.," Cells. Tissues. Organs, vol. 189, no. 5, pp. 317-26, Jan. 2009.

[63] K. Akeda, H. S. An, M. Okuma, M. Attawia, K. Miyamoto, E. J.-M. a Thonar, M. E. Lenz, R. L. Sah, and K. Masuda, "Platelet-rich plasma stimulates porcine articular chondrocyte proliferation and matrix biosynthesis.," Osteoarthritis Cartilage, vol. 14, no. 12, pp. 1272-80, Dec. 2006. 
[64] A. Spreafico, F. Chellini, B. Frediani, G. Bernardini, S. Niccolini, T. Serchi, G. Collodel, A. Paffetti, V. Fossombroni, M. Galeazzi, R. Marcolongo, and A. Santucci, "Biochemical investigation of the effects of human platelet releasates on human articular chondrocytes.," J. Cell. Biochem., vol. 108, no. 5, pp. 1153-65, Dec. 2009.

[65] C. Kaps, a Loch, a Haisch, H. Smolian, G. R. Burmester, T. Häupl, and M. Sittinger, "Human platelet supernatant promotes proliferation but not differentiation of articular chondrocytes.," Med. Biol. Eng. Comput., vol. 40, no. 4, pp. 485-90, Jul. 2002.

[66] C. Gaissmaier, J. Fritz, T. Krackhardt, I. Flesch, W. K. Aicher, and N. Ashammakhi, "Effect of human platelet supernatant on proliferation and matrix synthesis of human articular chondrocytes in monolayer and three-dimensional alginate cultures.," Biomaterials, vol. 26, no. 14, pp. 1953-60, May 2005.

[67] J. Duan, W. Kuang, J. Tan, H. Li, Y. Zhang, K. Hirotaka, and K. Tadashi, “Differential effects of platelet rich plasma and washed platelets on the proliferation of mouse MSC cells.," Mol. Biol. Rep., vol. 38, no. 4, pp. 2485-90, Apr. 2011.

[68] J. van den Dolder, R. Mooren, A. P. G. Vloon, P. J. W. Stoelinga, and J. a Jansen, “Platelet-rich plasma: quantification of growth factor levels and the effect on growth and differentiation of rat bone marrow cells.," Tissue Eng., vol. 12, no. 11, pp. 3067-73, Nov. 2006.

[69] O. Kilian, I. Flesch, S. Wenisch, B. Taborski, A. Jork, R. Schnettler, and T. Jonuleit, "Effects of platelet growth factors on human mesenchymal stem cells and human endothelial cells in vitro.," Eur. J. Med. Res., vol. 9, no. 7, pp. 337-344, 2004.

[70] S. S. Lin, R. Landesberg, H. S. Chin, J. Lin, S. B. Eisig, and H. H. Lu, “Controlled release of PRP-derived growth factors promotes osteogenic differentiation of human mesenchymal stem cells.," Conf. Proc. IEEE Eng. Med. Biol. Soc., vol. 1, pp. 4358-61, Jan. 2006.

[71] A. Mishra, P. Tummala, A. King, B. Lee, M. Kraus, V. Tse, and C. R. Jacobs, “Buffered platelet-rich plasma enhances mesenchymal stem cell proliferation and chondrogenic differentiation.," Tissue Eng. Part C. Methods, vol. 15, no. 3, pp. 431-5, Sep. 2009.

[72] J. P. Krüger, S. Hondke, M. Endres, A. Pruss, A. Siclari, and C. Kaps, "Human platelet-rich plasma stimulates migration and chondrogenic differentiation of human subchondral progenitor cells.," J. Orthop. Res., vol. 30, no. 6, pp. 845-52, Jun. 2012.

[73] X. Xie, Y. Wang, C. Zhao, S. Guo, S. Liu, W. Jia, R. S. Tuan, and C. Zhang, “Comparative evaluation of MSCs from bone marrow and adipose tissue seeded in PRP-derived scaffold for cartilage regeneration.," Biomaterials, vol. 33, no. 29, pp. 7008-18, Oct. 2012.

[74] E. Rubio-Azpeitia and I. Andia, "Partnership between platelet-rich plasma and mesenchymal stem cells: in vitro experience," Muscle, Ligaments Tendons J., vol. 4, no. 1, pp. 52-62, 2014. 
[75] E. Anitua, J. J. Aguirre, J. Algorta, E. Ayerdi, A. I. Cabezas, G. Orive, and I. Andia, "Effectiveness of autologous preparation rich in growth factors for the treatment of chronic cutaneous ulcers.," J. Biomed. Mater. Res. B. Appl. Biomater., vol. 84, no. 2, pp. 415-21, Feb. 2008.

[76] M. Takeuchi, N. Kamei, R. Shinomiya, T. Sunagawa, O. Suzuki, H. Kamoda, S. Ohtori, and M. Ochi, "Human platelet-rich plasma promotes axon growth in brain-spinal cord coculture.," Neuroreport, vol. 23, no. 12, pp. 712-6, Aug. 2012.

[77] J. L. Alio, F. Arnalich-Montiel, and A. E. Rodriguez, "The role of 'eye platelet rich plasma' (E-PRP) for wound healing in ophthalmology.," Curr. Pharm. Biotechnol., vol. 13, no. 7, pp. 1257-65, Jun. 2012.

[78] X.-H. Li, X. Zhou, S. Zeng, F. Ye, J.-L. Yun, T.-G. Huang, H. Li, and Y.-M. Li, “Effects of intramyocardial injection of platelet-rich plasma on the healing process after myocardial infarction.," Coron. Artery Dis., vol. 19, no. 5, pp. 363-70, Aug. 2008.

[79] Z. Dong, B. Li, B. Liu, S. Bai, G. Li, A. Ding, J. Zhao, and Y. Liu, "Platelet-rich plasma promotes angiogenesis of prefabricated vascularized bone graft.," J. Oral Maxillofac. Surg., vol. 70, no. 9, pp. 2191-7, Sep. 2012.

[80] T. M. Bielecki, T. S. Gazdzik, J. Arendt, T. Szczepanski, W. Król, and T. Wielkoszynski, "Antibacterial effect of autologous platelet gel enriched with growth factors and other active substances: an in vitro study." J. Bone Joint Surg. Br., vol. 89, no. 3, pp. 417-20, Mar. 2007.

[81] M. A. Smith and W. T. Smith, "Emerging techniques in orthopaedics: platelet-rich plasma.," Orthop. Nurs., vol. 30, no. 4, pp. 260-3; quiz 264-5, Jan. 2011.

[82] B. L. Eppley, W. S. Pietrzak, and M. Blanton, "Platelet-rich plasma: a review of biology and applications in plastic surgery.," Plast. Reconstr. Surg., vol. 118, no. 6, p. 147e159e, Nov. 2006.

[83] A. Mishra, K. Harmon, J. Woodall, and A. Vieira, "Sports medicine applications of platelet rich plasma.," Curr. Pharm. Biotechnol., vol. 13, no. 7, pp. 1185-95, Jun. 2012.

[84] L. E. Loss, G. A. Deitrick, and R. G. Duff, "A prospective randomized trial of autologous platelet-derived wound healing factors for treatment of chronic nonhealing wounds: a preliminary report.," J. Vasc. Surg., vol. 16, no. 1, pp. 125-6; author reply 126-8, Jul. 1992.

[85] T. Yuan, S.-C. Guo, P. Han, C.-Q. Zhang, and B.-F. Zeng, "Applications of leukocyteand platelet-rich plasma (L-PRP) in trauma surgery.," Curr. Pharm. Biotechnol., vol. 13, no. 7, pp. 1173-84, Jun. 2012.

[86] A. P. Sclafani, "Applications of Platelet-Rich Fibrin Matrix in Facial Plastic Surgery," 2009.

[87] A. Wang-Saegusa, R. Cugat, O. Ares, R. Seijas, X. Cuscó, and M. Garcia-Balletbó, “Infiltration of plasma rich in growth factors for osteoarthritis of the knee short-term ef- 
fects on function and quality of life.," Arch. Orthop. Trauma Surg., vol. 131, no. 3, pp. 311-7, Mar. 2011.

[88] G. Crovetti, G. Martinelli, M. Issi, M. Barone, M. Guizzardi, B. Campanati, M. Moroni, and A. Carabelli, "Platelet gel for healing cutaneous chronic wounds.," Transfus. Apher. Sci., vol. 30, no. 2, pp. 145-51, Apr. 2004.

[89] A. A. Akingboye, S. Giddins, P. Gamston, A. Tucker, H. Navsaria, and C. Kyriakides, "Application of autologous derived-platelet rich plasma gel in the treatment of chronic wound ulcer: diabetic foot ulcer.," J. Extra. Corpor. Technol., vol. 42, no. 1, pp. 20-9, Mar. 2010.

[90] M. Napolitano, S. Matera, M. Bossio, A. Crescibene, E. Costabile, J. Almolla, H. Almolla, F. Togo, C. Giannuzzi, and G. Guido, "Autologous platelet gel for tissue regeneration in degenerative disorders of the knee.," Blood Transfus., vol. 10, no. 1, pp. 72-7, Jan. 2012.

[91] P. A. M. Everts, M. M. Hoogbergen, T. A. Weber, R. J. J. Devilee, G. van Monftort, and I. H. J. T. de Hingh, "Is the use of autologous platelet-rich plasma gels in gynecologic, cardiac, and general, reconstructive surgery beneficial?," Curr. Pharm. Biotechnol., vol. 13, no. 7, pp. 1163-72, Jun. 2012.

[92] L. H. Redler, S. a Thompson, S. H. Hsu, C. S. Ahmad, and W. N. Levine, "Plateletrich plasma therapy: a systematic literature review and evidence for clinical use.," Phys. Sportsmed., vol. 39, no. 1, pp. 42-51, Feb. 2011.

[93] E. Lopez-Vidriero, K. a. Goulding, D. a. Simon, D. H. Johnson, and M. Sanchez, "Poor standardization in Platelet-rich Therapies Hampers Advancement," Arthrosc. J. Arthrosc. Relat. Surg., vol. 26, no. 6, pp. 724-725, Jun. 2010.

[94] J. M. Delong, R. P. Russell, and A. D. Mazzocca, "Platelet-rich plasma: The PAW classification system," Arthrosc. - J. Arthrosc. Relat. Surg., vol. 28, no. 7, pp. 998-1009, 2012. 
